\title{
Los salvadoreños opinan sobre los derechos humanos y la gestión de la Procuraduría
}

\author{
Instituto Universitario de Opinión Pública
}

\section{Resumen}

Entre el 7 y el 14 de febrero de 1998, el IUDOP realizó un sondeo de opinión pública para conocer la opinión de los salvadoreños sobre la situación de los derechos humanos en El Salvador y evaluar el último trienio del trabajo de la Procuraduría para la Defensa de los Derechos Humanos. Los resultados mostraron que los salvadoreños piensan que el respeto a los derechos humanos ha mejorado en el país, y que la ola delincuencial que lo azota es la principal responsable del irrespeto hacia ellos; en cuanto a la Procuraduría, los ciudadanos mostraron una actitud muy favorable hacia el trabajo de la misma en los últimos tres años y esperan que el próximo Procurador fortalezca la protección de los más desamparados.

\section{Introducción}

El tema de los derechos humanos ha sido siempre fundamental para el país. El respeto de las libertades fundamentales, la observancia de la justi- cia y la protección de la vida humana son aspectos que no siempre han convivido entre los salvadoreños; la ausencia de éstos, más bien, ha sido la norma general y ello ha hecho de este pequeño país centroamericano una nación conflictiva. Los 
acuerdos de paz firmados en 1992 y que pusieron fin a la guerra civil fueron orientados en gran medida a intentar subsanar esas carencias fundamentales, es decir, a fortalecer un sistema en que el respeto a los derechos humanos fuese una parte esencial. Para ello, se disolvieron antiguas y represivas instituciones y se crearon o transformaron otras. Una de ellas fue la Procuraduría para la Defensa de los Derechos Humanos (PDDH), organismo mediante el cual se buscaba institucionalizar un sistema de protección, para los ciudadanos, de los abusos del Estado. En marzo de 1998, la Procuraduría cumplió seis años de existencia, los últimos tres bajo la responsabilidad de Victoria de Avilés que dio a la institución una relevancia singular en la vida política del país. En tal sentido, el Instituto Universitario de Opinión Pública desarrolló un sondeo para conocer lo que los salvadoreños piensan acerca del tema de los derechos humanos y para permitir que los adultos salvadoreños evalúen el desempeño de la Procuradora en la defensa de los derechos fundamentales.

El presente artículo constituye el resumen de algunos resultados fundamentales del estudio de la opinión pública y se divide en ocho apartados. El primero es una descripción de la muestra y metodología empleada para llevar a cabo el sondeo. El segundo presenta los resultados del estudio referentes a la concepción que tienen los salvadoreños sobre los derechos humanos y su observancia en el país. El capítulo tres aborda los datos que ofrecen las opiniones sobre el estado de respeto a los derechos humanos. El apartado cuatro se concentra en las instituciones que defienden estos derechos, y la sección siguiente, la número cinco, presenta las opiniones sobre la Procuraduría para la Defensa de los Derechos Humanos. El apartado seis presenta las expectativas de la población con respecio a la próxima administración de la Procuraduría, y el capítulo siete muestra de manera breve una comparación entre los resultados de la presente encuesta y los obtenidos por un estudio similar hecho en 1995, para recoger la evolución de las opiniones en el trienio 95-98. Finalmente, el artículo cierra con las conclusiones donde se resumen los aspectos más relevantes del estudio.

\section{Encuesta y población encuestada}

En los dos primeros fines de semana del mes de febrero de 1998, el Instituto Universitario de Opinión Pública (IUDOP) de la Universidad Cen- troamericana "José Simeón Cañas" (UCA), realizó una encuesta de opinión pública con el objeto de conocer la forma de pensar de los salvadoreños sobre tres grandes temas, dos de ellos tienen que ver con el área de los derechos humanos: en primer lugar, se buscaba recoger las opiniones sobre el tema general de los derechos humanos en el país; en segundo lugar, cómo evalúan los salvadoreños el trabajo de la Procuraduría para la Defensa de los Derechos Humanos en los últimos tres años de su gestión; finalmente, la encuesta abordaba de manera complementaria el tema político del país, preguntando por algunas opiniones acerca de las coyunturas políticas y las preferencias partidistas de los salvadoreños.

El cuestionario usado para el sondeo se componía básicamente de cuatro partes. La primera, como ya es costumbre, recogía los datos demográficos de las personas: sexo, edad, escolaridad, condición de empleo y religión; además de aquella información que se refería a ciertas condiciones del entrevistado, como estrato socioeconómico, departamento y municipio de residencia. En este mismo apartado, aunque no están direclamente relacionados con el ámbito demográfico, se preguntó a los encuestados sobre el principal problema del país y la frecuencia con que atiende a los diferentes medios de comunicación (prensa, radio y televisión). En la segunda parte del cuestionario se obtenía la concepción de derechos humanos que tienen los salvadoreños; se les pidió que citaran el derecho humano más importante, los entes llamados a defenderlos y el tipo de personas a quienes se les violan más sus derechos. Contenía, además, una serie de reactivos en una escala tipo likert de acuerdo/desacuerdo referida a valores y opiniones sobre la situación de derechos humanos en el país, los derechos laborales y la responsabilidad del gobierno en el respeto a los derechos fundamentales de la persona. También se exploraba el conocimiento de la población sobre el respeto a los derechos humanos en la empresa privada y el sector público; además de indagar sobre la institución que a juicio de los ciudadanos defiende mejor los derechos humanos tanto en nuestro país como en la comunidad a la que pertenecen. El tercer bloque estaba constituido por algunas preguntas relacionadas con el conocimiento de la Procuraduría para la Defensa de los Derechos Humanos (PDDH) y la valoración acerca de su forma de trabajar en la actualidad. Además, se evaluaba el quehacer de las instituciones cuya responsabilidad tiene que 
ver con la vigilancia de los derechos ciudadanos. Para terminar este bloque se recopiló información acerca de lo que se debe hacer, en opinión de los entrevistados, para que la situación de los derechos humanos mejore en el país. En la última parte se solicitó la opinión de la población respecto a diversos tópicos de orden político: la utilidad del Plan de nación en el desarrollo del país; el intento de destitución del secretario general del Partido Demócrata Cristiano, el personaje que sería el mejor candidato a la presidencia de El Salvador y el punto de vista respecto a Francisco Flores y Eduardo Tenorio como posibles candidatos a presidente. Se inquirió también acerca de si el país está listo para tener como presidenta a una mujer y lo que deben hacer los partidos de centro de cara a las próximas elecciones; finalmente se preguntó por la opción de voto de los ciudadanos en el presente y el partido político que tiene más probabilidades de ganar las elecciones en 1999.

La muestra nacional se diseñó de tal manera que representase lo más fielmente posible la totalidad de la población salvadoreña, y se estableció en proporción a la distribución departamental que arrojó el Censo Nacional de Población de 1992 y el último informe disponible de la Encuesta de
Hogares de Propósitos Múltiples de la Dirección de Información del Ministerio de Economía. La cuota muestral incluyó 37 municipios de los catorce departamentos de la República. En cada departamento, la muestra se dividió en dos grandes sectores: urbano y rural. El primero fue dividido en cinco estratos: alto, medio-alto, medio-bajo, obrero y marginal. El sector rural se dejó como una categoría única por las dificultades de encontrar criterios de tipificación en el campo. En el muestreo se consideraron también cuotas por sexo y edad de los encuestados, de tal manera que cada boleta estaba marcada con las características que debía cumplir el encuestado para ser contemplado en la investigación.

La aplicación del cuestionario se hizo por aproximación no sistemática a los hogares ubicados en los municipios y las zonas definidas aleatoriamente. Los entrevistadores explicaban a las personas abordadas los objetivos y el tema de la encuesta. En cada caso se entrevistó únicamente a personas que quisieran contestar (una persona por hogar) y que cumplieran con los requerimientos descritos en la boleta para completar la cuota muestral.

Cuadro 1

Distribución de la población encuestada según departamento y sector social

\begin{tabular}{|c|c|c|c|c|c|c|c|c|}
\hline \multirow[b]{2}{*}{ Departamento } & \multirow[b]{2}{*}{ Alto } & \multirow[b]{2}{*}{ Medio-alto } & \multicolumn{2}{|c|}{ Sector social } & \multirow[b]{2}{*}{ Marginal } & \multirow[b]{2}{*}{ Rural } & \multicolumn{2}{|c|}{ Todos } \\
\hline & & & Medio-bajo & Obrero & & & $\mathbf{N}$ & $\%$ \\
\hline Ahuachapán & 3 & 4 & 4 & 7 & 4 & 40 & 62 & 5.2 \\
\hline Santa Ana & 7 & 13 & 13 & 20 & 13 & 42 & 108 & 9.1 \\
\hline Sonsonate & 4 & 10 & 9 & 14 & 10 & 34 & 81 & 6.8 \\
\hline La Libertad & 7 & 18 & 12 & 23 & 15 & 47 & 122 & 10.3 \\
\hline Chalatenango & 3 & 4 & 4 & 7 & 4 & 24 & 46 & 3.9 \\
\hline San Salvador & 34 & 57 & 61 & 98 & 59 & 46 & 355 & 29.9 \\
\hline Cabañas & 2 & 3 & 3 & 5 & 2 & 13 & 28 & 2.4 \\
\hline Cuscatlán & 2 & 5 & 5 & 6 & 5 & 15 & 38 & 3.2 \\
\hline San Vicente & 2 & 4 & 4 & 6 & 4 & 14 & 34 & 2.9 \\
\hline La Paz & 3 & 7 & 8 & 12 & 8 & 19 & 57 & 4.8 \\
\hline Usulután & 4 & 7 & 8 & 12 & 8 & 35 & 74 & 6.2 \\
\hline San Miguel & 6 & 11 & 14 & 18 & 13 & 20 & 82 & 6.9 \\
\hline Morazán & 1 & 4 & 4 & 6 & 4 & 21 & 40 & 3.4 \\
\hline La Unión & 4 & 6 & 6 & 10 & 6 & 30 & 62 & 5.2 \\
\hline Todos & 82 & 153 & 155 & 244 & 155 & 400 & $1 / 89$ & \\
\hline$\%$ & 6.9 & 12.9 & 13.0 & 20.5 & 13.0 & 33.6 & & 100 \\
\hline
\end{tabular}


La muestra linal obtenida fue de 1,189 encueslas válidas, con un margen de error estimado de $+/$ - 0.04 (cuatro por ciento). El 49.1 por ciento de los entrevistados pertenecían al sexo masculino y el 50.9 por ciento, al sexo femenino. La edad promedio fue de 36.8 años con una desviación típica de 14.4 años. Los encuestados tenían un promedio general de 7.6 años de estudio y el 53.8 por ciento de ellos estaban empleados en la actualidad o poseían un trabajo propio. El Cuadro 1 muestra la distribución de la población encuestada por departamento y estrato social.

\section{Conceptos sobre los derechos humanos}

Después de haber enfrentado un conllicto bélico por doce años, ¿qué entienden los salvadoreños por derechos humanos?, ¿cuál derecho humano es el más importante? A pesar de su aparente simpleza, la pregunta no es fácil para la mayoría de los ciudadanos salvadoreños. Un poco más de la quinta parte de la población —el 21.3 por ciento- no supo dar una definición de derechos humanos, a pesar de que por más de diez años diversas organizaciones han insistido y trabajado en la necesidad de que los ciudadanos entiendan y ejerzan sus derechos fundamentales. El 22.1 por ciento los concibe como los "derechos de todos"; el 21 por ciento los definió como respeto; el 10.8 por ciento los concibe como aquello que "ayuda a la gente"; el 9.8 por ciento los definió como lo que "nos protege", y el resto de consultados se refirieron a ellos como "libertad", justicia, igualdad, entre otras respuestas.

A pesar de que un segmento importante de la población sigue sin tener un concepto definido de lo que son los derechos humanos, las ideas sobre el término se pueden ubicar en dos grandes áreas: por un lado, existe un concepto que se refiere a la universalidad de los mismos en cuanto derechos que se poseen como personas (derechos de todos, respeto); por otro lado, hay una idea que los define como una herramienta de prolección para los más desvalidos (ayuda a la gente, "lo que nos protege"). Pero, en todo caso, estos resultados señalan un mayor nivel de complejidad del concepto en comparación con el sondeo realizado a principios de 1995. En esa ocasión, la mayor parte de las respuestas a esta pregunta se concentraban en el respeto (ver Instituto Universitario de Opinión Pública, 1995a). En la presente pesquisa, además, fue posible encontrar diferencias entre los ciudadanos que provienen de distintos sectores sociales: los resultados señalaron que el carácter universal de los derechos humanos y la concepción de los mismos como respeto fueron expresados con más frecuencia por las personas que habitan en zonas urbanas y que pertenecen a los estratos socioeconómicamente más altos; mientras que los ciudadanos de sectores más bajos se refirieron más al carácter protector y asistencial de los derechos humanos.

Pero, quizás, el dato más revelador sobre lo que significan los derechos humanos para los salvadoreños se encuentra en lo que ellos delinen como el derecho humano más importante. De acuerdo con el Cuadro 2 , un poco más de la tercera parte de los consultados - cl 34.9 por ciento- mencionaron el derecho a la vida como lo más importante; le sigue un 9.2 por ciento que se refirió al respeto entre los ciudadanos ("respeto hacia los demás"); el 7.7 por ciento dijo que los derechos de los niños son más importantes y un 5.6 por ciento sostuvo que la libertad es el derecho más importante. No puede dejar de señalarse el hecho de que nuevamente un porcentaje importante de los entrevistados -el 19.2 por ciento- no supieron dar una respuesta a la pregunta; esta proporción es aún mayor entre los ciudadanos de sectores obreros, marginales y rurales.

Más allá de la aparente dispersión de los datos, dado que las respuestas se llegaron a categorizar en nueve distintos tipos de ideas', los resultados anteriores ponen en evidencia lo que para los ciu-

1. Las categorías originales que aparecen en el informe de la encuesta eran aún más numerosas. Para efectos del 
dadanos sería lo más valioso —en términos de derechos básicos- en el momento actual. El derecho a la vida y el respeto —entendido éste último como cl celo por cuidar la integridad física de las personas- constituyen prácticamente el núcleo del sistema de derechos humanos, lo que se entiende como lo más básico; el hecho de que un poco más del 40 por ciento de los consultados se refieran a esa dimensión podría estar señalando una de las preocupaciones más fuertes de la opinión pública en la actualidad: la precaric-

dad de la vida a causa de la violencia y la delincuencia. Si a los anteriores derechos se suma la referencia por la libcrtad, otro derecho fundamental, se tiene que más de la mitad de los salvadoreños estarían subrayando el aspecto esencial del tema de los derechos fundamentales.

\section{Figura 1}

Opinión sobre el derecho humano más importante

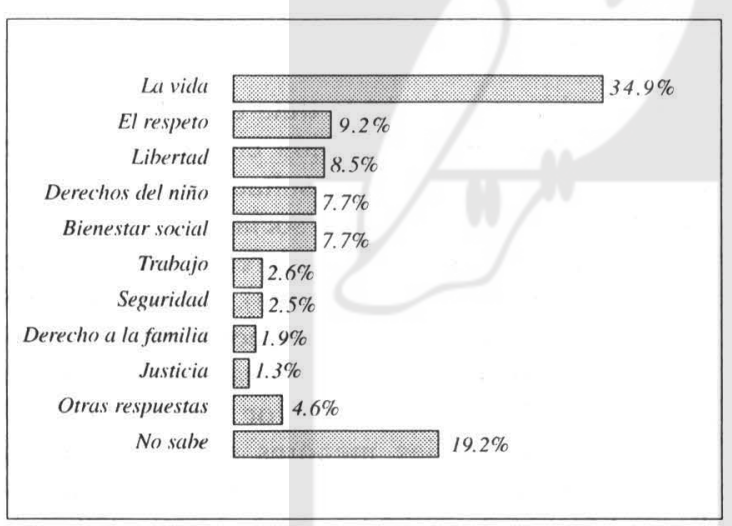

Ahora dígame, por favor, ¿cuál es el derecho humano más importante para usted?

\section{Opiniones sobre el respeto a los derechos humanos}

Definido el concepto de derechos humanos para los salvadoreños, la pesquisa de la UCA recogió las opiniones de los ciudadanos sobre el nivel de respeto hacia los mismos en la actualidad. Para comenzar, el 48.6 por ciento de los consultados no estuvieron de acuerdo con la idea de que en El Salvador existe respeto a los derechos humanos actualmente; en cam-

bio, un porcentaje cercano al 44.1 por ciento opinó que sí existe respeto hacia estos derechos en el país; el resto -el 7.3 por ciento- se abstuvo de responder a la pregunta. Lo anterior significa que la población está dividida casi por la mitad respecto a su opinión sobre el respeto a los derechos humanos; aunque la gente tiende un poco más a responder de forma negativa, la diferencia de opiniones no es tan grande y prácticamente se puede asumir que la otra mitad de la población ve las cosas de forma positiva. Sin embargo, esta distribución de opiniones no es igual para todos los grupos sociales definidos por el estrato socioeconómico y el nivel educativo. Según las cifras mostradas en el Cuadro 2, las expresiones positivas acerca del respeto a los derechos humanos en el país son más frecuentes en los grupos socioeconómicos pobres; en la medida en que se "asciende" en la escala social, las opiniones sobre el estado de los derechos humanos son menos optimistas. Lo mismo sucede al comparar los datos según el nivel educativo de los entrevistados: las personas que tienen poca o ninguna formación académica presentan los juicios más esperanzados sobre el respeto a los derechos humanos en el país, mientras que los ciudadanos que poseen mayor nivel de instrucción escolar - los universitarios- se revelan más escépticos.

manejo analítico, tales categorías se agruparon aún más; los resultados se exponen en la Figura 1 (ver Instituto Universitario de Opinión Pública, 1998). 
Cuadro 2

Opinión sobre la existencia de respeto a los derechos humanos en El Salvador según variables (En porcentajes)

\begin{tabular}{|c|c|c|c|c|c|}
\hline \multirow[b]{2}{*}{ Variables } & \multicolumn{4}{|c|}{ Opinión } & \multirow[b]{2}{*}{$\begin{array}{l}\text { No } \\
\text { sabe }\end{array}$} \\
\hline & $\begin{array}{c}\text { Muy en } \\
\text { desacuerdo }\end{array}$ & $\begin{array}{c}\text { Algo en } \\
\text { desacuerdo }\end{array}$ & $\begin{array}{l}\text { Algo de } \\
\text { acuerdo }\end{array}$ & $\begin{array}{l}\text { Muy de } \\
\text { acuerdo }\end{array}$ & \\
\hline \multicolumn{6}{|l|}{ Estrato } \\
\hline Alto & 29.3 & 29.3 & 30.5 & 6.1 & 4.9 \\
\hline Medio-alıo & 30.7 & 27.5 & 30.7 & 7.2 & 3.9 \\
\hline Medio-bajo & 42.6 & 18.7 & 26.5 & 9.0 & 3.2 \\
\hline Obrero & 36.5 & 14.8 & 26.2 & 15.2 & 7.4 \\
\hline Marginal & 26.5 & 18.7 & 36.8 & 12.3 & 5.8 \\
\hline Rural & 19.0 & 18.8 & 29.8 & 21.3 & 11.3 \\
\hline \multicolumn{6}{|l|}{ Estudios } \\
\hline Ninguno & 17.4 & 12.2 & 39.0 & 20.3 & 11.0 \\
\hline Primaria & 22.4 & 19.3 & 27.2 & 21.3 & 9.8 \\
\hline Plan básico & 32.8 & 17.7 & 28.6 & 12.5 & 8.3 \\
\hline Bachillerato & 37.9 & 23.4 & 24.8 & 10.7 & 3.3 \\
\hline Superior & 35.0 & 24.0 & 31.9 & 5.1 & 3.9 \\
\hline Todos & 28.8 & 19.8 & 29.7 & 14.4 & 7.3 \\
\hline
\end{tabular}

A continuación le voy a leer una serie de opiniones sobre distintos temas relacionados con los derechos humanos; digame, por favor, si está muy de acuerdo, algo de acuerdo, algo en desacuerdo o muy en desacuerdo con cada una: En El Salvador existe respeto a los derechos humanos.

Lo anterior podría estar relacionado con la comprensión misma del concepto de los derechos humanos. Ya se ha visto que las personas que pertenecen a los estratos más desposeídos y marginados de la sociedad son las que raramente conocen o tienen una idea sobre lo que son los derechos fundamentales; más aún, muchos los conciben como la condición mínima para poder vivir -independientemente de la calidad de vida. Enfrentados al hecho de tener que juzgar una condición que entienden en su situación más básica, muchos ciudadanos la califican de forma positiva precisamente porque no terminan de entender toda la complejidad del concepto. Esto no invalida en forma alguna las opiniones de este segmento de la población; más bien, pone en evidencia que una parte significativa de la población elabora sus juicios sobre sus realidades y condiciones de vida más básicas. En cambio, los compatriotas con una mejor posición social, tanto en términos económicos como de formación educativa, suelen evaluar las condiciones de respeto a los derechos humanos con base en criterios más complejos y, en general, tienen una actitud más crítica sobre la situación del país en esa área.

Sin embargo, cuando se trata de definir al grupo más vulnerable en relación con el amparo de los derechos humanos, los resultados son más consistentes en todos los grupos sociales o demográficos. Gran parte de los salvadoreños piensan que los más pobres ( 31.2 por ciento), los niños $(29.8$ por ciento) y las mujeres ( 10.8 por ciento) constituyen el tipo de personas a los cuales se les violan los derechos humanos con mayor frecuencia en El Salvador; porcentajes menores señalaron a los campesinos, ancianos y jóvenes. Los datos no indican diferencias consistentes y significativas en las opiniones relacionadas con el estrato social, aunque la mención a los niños se halla con porcentajes más altos en los sectores medio-bajos que en los demás y la referencia a las mujeres es más frecuente entre los más ricos. En términos de nivel educativo, las personas que han estudiado hasta bachillerato son quienes muestran el mayor porcentaje de preocupación por los niños y las mujeres. En todo caso, las respuestas a la pregunta muestran que los salvadoreños están conscientes 
de la necesidad de proteger los derechos de los grupos de personas usualmente más desvalidas y vulnerables de la población, las cuales paradójicamente constituyen la mayoría de los ciudadanos.

De hecho, la encuesta reveló que más de la mitad de los consultados -el 56.4 por cientopiensan que las autoridades del país no se preocupan por defender los derechos humanos de todos los salvadoreños; frente a una tercera parte -el 32.6 por ciento- que piensa lo contrario $y$ un 11.1 por ciento que no respondió a la pregunta. El sondeo de la UCA encontró una elevada correlación entre la opinión sobre el respeto a los derechos humanos en el país y la opinión de si el gobierno se preocupa por los derechos humanos de todos los salvadoreños. En otras palabras, las personas que sostenian que no existe respeto hacia ellos en el país, por lo general también afirmaban que el gobierno no se preocupa por los derechos humanos de todos los salvadoreños. Según el Cuadro 3, la opinión negativa acerca de esta actitud del gobierno se encuentra con más frecuencia en los sectores medios de la población y los ciudadanos con mayores niveles de formación educativa que en cualquier otro grupo de personas. Aunque la encuesta también mostró que en esta opinión interviene mucho la afiliación política de las personas: los consultados con simpatía hacia el partido de gobiemo mostraron opiniones más favorables hacia la función del gobierno en la tarea de defender los derechos humanos, mientras que los correligionarios de los partidos de la oposición política expresaron juicios más desfavorables.

\section{Las instituciones que defienden los derechos humanos... y las que los violan}

Relacionado con lo anterior, se les preguntó a los salvadoreños sobre la responsabilidad o, mejor dicho, el responsable principal de defender los derechos humanos. El 30.2 por ciento respondió que el gobierno es el principal encargado de hacerlo; le sigue el 16.7 por ciento que contestó que los

\section{Cuadro 3}

Opinión de si el actual gobierno se preocupa por los derechos humanos de todos los salvadoreños según variables

(En porcentajes)

\begin{tabular}{|c|c|c|c|c|c|}
\hline \multirow[b]{2}{*}{ Variables } & \multicolumn{5}{|c|}{ Opinión } \\
\hline & $\begin{array}{c}\text { Muy en } \\
\text { desacuerdo }\end{array}$ & $\begin{array}{c}\text { Algo en } \\
\text { desacuerdo }\end{array}$ & $\begin{array}{l}\text { Algo de } \\
\text { acuerdo }\end{array}$ & $\begin{array}{l}\text { Muy de } \\
\text { acuerdo }\end{array}$ & $\begin{array}{c}\text { No } \\
\text { sabe }\end{array}$ \\
\hline \multicolumn{6}{|l|}{ Estrato } \\
\hline Alto & 32.9 & 24.4 & 24.4 & 7.3 & 11.0 \\
\hline Medio-alto & 42.5 & 22.9 & 19.6 & 7.8 & 7.2 \\
\hline Medio-bajo & 48.4 & 16.8 & 21.9 & 5.8 & 7.1 \\
\hline Obrero & 41.4 & 19.7 & 20.1 & 9.0 & 9.8 \\
\hline Marginal & 35.5 & 18.7 & 22.6 & 11.0 & 12.3 \\
\hline Rural & 30.0 & 17.3 & 24.8 & 13.5 & 14.5 \\
\hline \multicolumn{6}{|l|}{ Estudios } \\
\hline Ninguno & 24.4 & 15.7 & 27.9 & 9.9 & 22.1 \\
\hline Primaria & 35.0 & 18.8 & 21.8 & 13.7 & 10.6 \\
\hline Plan básico & 39.6 & 16.7 & 20.8 & 9.4 & 13.5 \\
\hline Bachillerato & 43.5 & 19.2 & 23.4 & 8.4 & 5.6 \\
\hline Superior & 42.1 & 23.6 & 20.1 & 7.1 & 7.1 \\
\hline Todos & 37.3 & 19.1 & 22.5 & 10.1 & $I 1.1$ \\
\hline
\end{tabular}

A continuación le voy a leer una serie de opiniones sobre distintos temas relacionados con los derechos humanos. Dígame, por favor, si está muy de acuerdo, algo de acuerdo, algo en desacuerdo o muy en desacuerdo con cada una: El gobierno actual se preocupa por los derechos humanos de todos los salvadoreños. 
mismos ciudadanos son los más indicados para defender los derechos básicos; en una respuesta parecida, el 11.2 por ciento respondió que "todos" son responsables de la defensa de los derechos; el resto mencionó a instituciones concretas: la Procuraduría para la Defensa de los Derechos Humanos ( 7.4 por ciento), la Policía Nacional Civil (5.9 por ciento) y las instituciones del sector justicia (2.9 por ciento), entre otras respuestas.

Aunque tres de cada diez salvadoreños señalan al gobierno como el principal encargado de proteger los derechos fundamentales y otro porcentaje atribuye esa responsabilidad a instituciones específicas, una proporción nada despreciable de los entrevistados adviertieron la incumbencia propia o del ciudadano común en la defensa de estos derechos. Esto sucede especialmente entre los entrevistados de la clase media, lo cual pone en evidencia que los salvadoreños no siempre esperan que el gobierno sea el garante de los derechos fundamentales.

\section{Figura 2}

Instituciones que defienden mejor los derechos humanos en el país y la comunidad

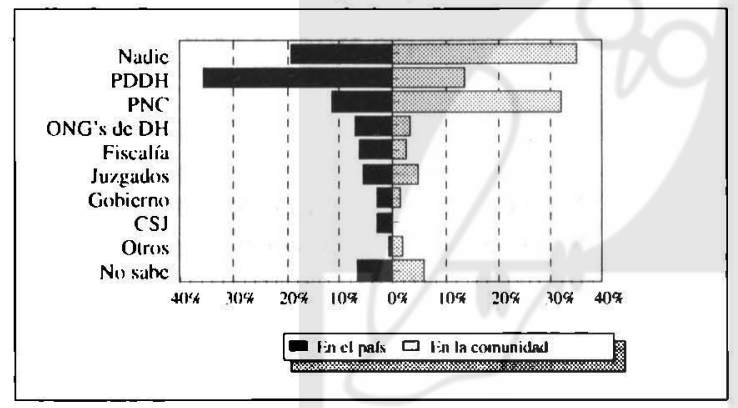

De las siguientes, ipodría decirme la institución que a su juicio defiende mejor los derechos humanos en nuestro pais/ en su comunidad?

En todo caso, la encuesta del IUDOP también consultó directamente a los ciudadanos sobre las instituciones del país que defienden mejor los derechos humanos. Esto en dos ámbitos: nacional y comunitario. Una encuesta similar, realizada entre septiembre y octubre de 1995, reveló que los ciudadanos no siempre pensaban que la institución que defendía mejor los derechos en el ámbito nacional lo hacía también en el ámbito comunitario (ver Instituto Universitario de Opinión Pública, 1995). Los resultados del presente sondeo confir- man esa tendencia e inclusive muestran opiniones más divergentes. A nivel nacional, más de la tercera parte de la población -el 35.8 por cientopiensa que la Procuraduría para la Defensa de los Derechos Humanos (PDDH) es la institución que defiende mejor los derechos humanos; le sigue la Policía Nacional Civil, con un 11.6 por ciento de las menciones; las organizaciones no gubernamentales de derechos humanos (IDHUCA, Tutela Legal) y otras instituciones gubernamentales: Fiscalía General de la República, juzgados, Corte Suprema de Justicia, etc. Sin embargo, una proporción importante de los entrevistados -el 19.5 por ciento- dijeron que ningún organismo en el país los defiende. A nivel comunitario, las respuestas se modificaron a favor de la PNC: el 32 por ciento de los entrevistados ven a la Policía Nacional Civil como la institución que defiende mejor los derechos básicos en las comunidades de vivienda de los salvadoreños; en este caso, sólo el 13.6 por ciento considera a la Procuraduría de Derechos Humanos como la principal defensora; otros encuestados señalaron a los juzgados (4.8 por ciento), las organizaciones no gubernamentales de derechos humanos (3.2 por ciento), la Fiscalía General de la República (2.3 por ciento) y el gobierno (1.5 por ciento), entre otras respuestas. Al igual que en el caso de la pregunta sobre las instituciones que defienden los derechos humanos a nivel nacional, las respuestas, en su mayoría, se concentraron en aquellas personas que afirmaron que nadie defiende estos derechos en la comunidad de residencia. Esta proporción sugiere que las personas piensan que las instituciones en general tienen menos capacidad para proteger los derechos humanos en la comunidad que en el ámbito nacional.

En ambos casos -en el ámbito nacional como en el comunitario-, la Procuraduría para la Defensa de los Derechos Humanos es más citada por las personas de estratos altos, medio-altos y por personas que gozan de niveles superiores de formación educativa; mientras que la Policía Nacional Civil encuentra opiniones más favorables por su trabajo en la defensa de los derechos entre los salvadoreños más desposeídos socioeconómicamente: los marginados y campesinos, los analfabetas y quienes cursaron hasta sexto grado.

Ahora bien, la Procuraduría para la Defensa de los Derechos Humanos recibe una mejor opinión por su desempeño a nivel nacional que en el ámbito comunitario; esto probablemente tiene relación 
con su tipo de trabajo - más institucional- a favor de los derechos básicos. La Policía Nacional Civil, en cambio, se ve más favorecida por las opiniones ciudadanas que le atribuyen un buen desempeño en el ámbito comunitario. Es probable que csta tendencia esté respondiendo a la más o menos constante presencia policial en las comunidades - algo que no sucede en el caso de la Procuraduría. Gran parte del trabajo de la policía se desarrolla en el campo, los barrios y las colonias de las ciudades, lo que la hace estar en contacto con los ciudadanos con más frecuencia que los delegados de la Procuraduría. A esta explicación habría que agregar otra que también parece plausible. El sondeo en cuestión mostró que mucha de la inquietud por el respeto a los derechos humanos de los salvadoreños está intensamente vinculada con la percepción sobre los niveles de violencia y delincuencia que vive la sociedad actualmente. De hecho, la encuesta reveló que la cuarla parte de la población (cl 25.7 por ciento) piensa que los delincuentes son quienes violan los derechos humanos con más frecuencia; a este porcentaje habría que agregar el 4.4 por ciento que señaló a las "maras" como los principales violadores de los derechos ${ }^{2}$. Las personas que piensan que los criminales son los violadores más frecuentes de los derechos humanos son aquéllos que, por otro lado, piensan que la policía es la mejor protectora de tales derechos. Ese es un pensamiento lógico: los policías protegen mejor los derechos ciudadanos precisamente porque combaten a los delincuentes; en la medida en que se produce esta asociación, en esa medida, la opinión sobre la PNC como defensora de los derechos aumenta.

Pero sobre quienes violan los derechos humanos, la encuesta de la UCA no sólo encontró opiniones que señalaban a los delincuentes; también reveló que algunos salvadoreños piensan que oras instancias violan los derechos humanos: el 16.5 por ciento dijo que la Policía Nacional Civil es la que viola más los derechos fundamentales; el 14.6 por ciento señaló al gobierno, y el 5.2 por ciento se refirió a la empresa privada, entre otras respuestas. Sin embargo, el 23.2 por ciento no supo responder a la pregunta.

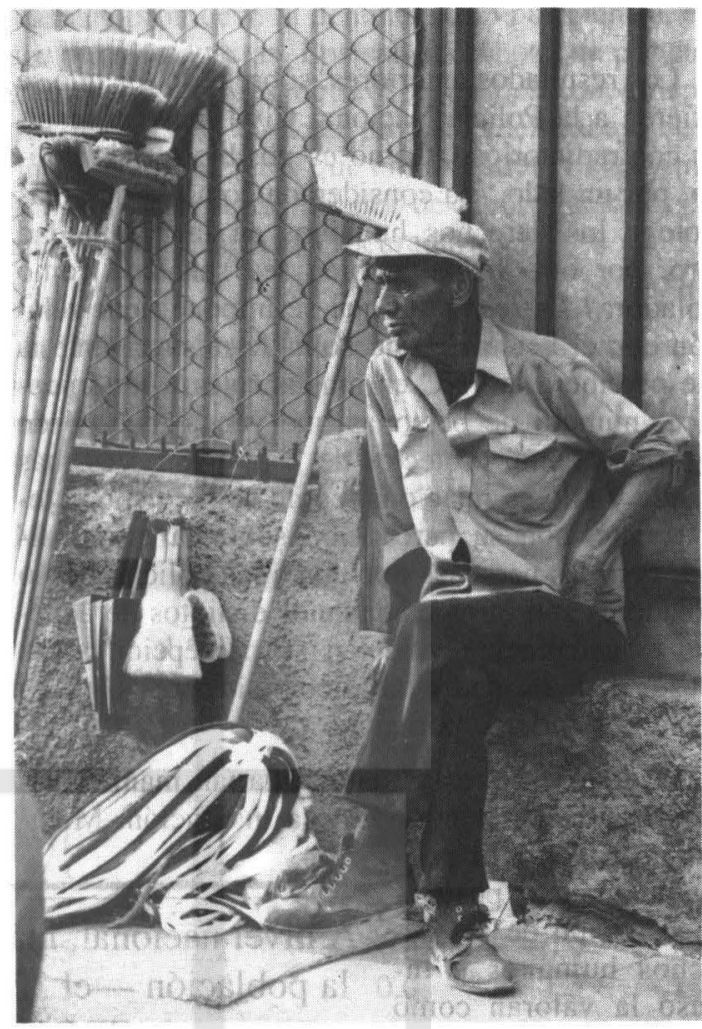

Figura 3

Opinión sobre los que violan más los derechos humanos en el país

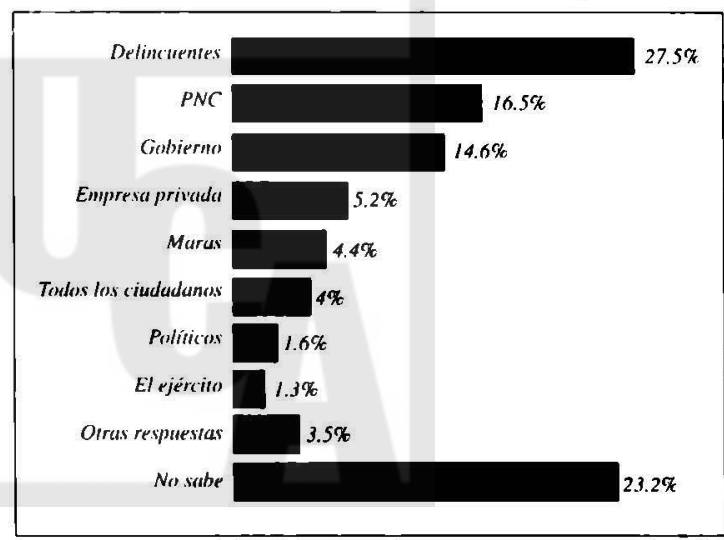

Para usted, ¿quién viola más los derechos humanos en nuestro pais?

2. Aunque las maras no pueden ser clasificadas directamente como delincuentes, buena parte de la población hace esa asociación y vincula a las pandillas con las acciones delincuenciales cuando señala a los delincuentes como los violadores de los derechos humanos. 
Los resultados anteriores, sobre todo los que se refieren a la Policía Nacional Civil, pueden resultar contradictorios. ¿Cómo es posible que la policía, por un lado, sea considerada como la que más protege los derechos humanos en la comunidad pero, por otro lado, también sea señalada como violadora? La respuesta que se impone tiene relación con el hecho de que no es la misma gente la que percibe a la PNC en ambos roles. Ciertamentc, el número de personas que ven al cuerpo de seguridad como protector de las personas es más grande y ello se relaciona, como se ha dicho anteriormente, con su percepción sobre la criminalidad; pero las personas que ven a los policías como violadores son otros ciudadanos distintos de aquéllos, y usualmente vinculan su percepción a los abusos de autoridad y faltas cometidas por algunos miembros de la corporación.

En todo caso, estos datos estarían manifestando el carácter polémico de esa institución. Mientras unos ven a la policía de manera positiva en el campo de los derechos humanos $\mathrm{e}$ incluso la valoran como la más adecuada para proteger a la población, otros se concentran en los reportes de la Procuraduría que afirman que la PNC es la institución del Estado que más viola estos derechos.

La pesquisa de la UCA recogió también ese carácter polémico

de la policía en el tema de los derechos humanos, al preguntar directamente a los ciudadanos si la Policía Nacional Civil es una de las instituciones que más viola los derechos humanos, como lo afirman los registros de la Procuraduría para la Defensa de los Derechos Humanos. Los resultados reiteran que la opinión pública está dividida sobre el tema. El 50.1 por ciento está en desacuerdo con la afirmación de que la policía es una de las instituciones que más viola los derechos humanos; en cambio, casi la otra mitad -el 43 por ciento- si piensa que la policía es una institución que los viola; el resto no supo responder a la pregunta. Aunque las opiniones en torno a la PNC dividen a la población general casi por la mitad, cuando se revisan las respuestas de los ciudadanos según los grupos sociales a los que pertenecen, pueden verse algunas disparidades en los estratos altos y los niveles educativos más bajos. En estos grupos prevalece la declaración de que la policía no es una institución violadora de los derechos humanos; en cambio, entre los más jóvenes y los correligionarios del partido FMLN, las opiniones más comunes compromelen la imagen del cuerpo policial, es decir, en estos conglomerados se suelen encontrar con más frecuencia referencias negativas hacia la función de la policía con respecto a los derechos humanos.

\section{Opiniones sobre la Procuraduría para la Defensa de los Derechos Humanos}

Como se dijo anteriormente, gran parte de la presente investigación fue diseñada para recoger lo que piensan los salvadoreños sobre el desempeño de la Procuraduría para la Defensa de los Derechos Humanos, sobre todo en el último trienio, es decir, durante la gestión de la Dra. Victoria Marina de Avilés. En general, las opiniones de los ciudadanos sobre la institución pueden considerarse positivas.

Para comenzar, la encuesta encontró que el 71.9 por ciento de los consultados conocían la Procuraduría de Derechos Humanos -y la supieron diferenciar de la Procuraduría General de la República-, frente al 28.1 por ciento que no la conocen. Esta institución sigue siendo más reconocida entre las personas que residen en el Area Metropolitana de San Salvador (AMSS), los sectores socioeconómicos ascendentes (altos y medios), los hombres - más que las mujeres-y universitarios o quienes poseen estudios superiores.

Aunque la tercera parte de la población consultada (33.5 por ciento) no supo identificar un logro 
de la PDDH y el 10 por ciento afirmó que tal institución no tiene logros en el último trienio, el resto mencionó los siguientes éxitos de la Procuraduría: ayuda, defiende y protege a la gente (17.4 por ciento); defiende los derechos humanos (8 por ciento); protege a los niños (7.3 por ciento); protege a las mujeres ( 7.3 por ciento), investiga casos y promueve la denuncia (5.5 por ciento), entre otras respuestas. Los salvadoreños que pertenecen a los sectores obreros y rurales son quienes resaltan más el carácter protector del trabajo de la institución, mientras que en los estratos alto y medio-alto se destaca la labor de investigación y denuncia que realiza la Procuraduría.

Cuadro 4

Principal logro de la Procuraduría para la Defensa de los Derechos Humanos en los últimos tres años según sector social

(En porcentajes)

\begin{tabular}{|c|c|c|c|c|c|c|c|}
\hline \multirow[b]{2}{*}{ Principal logro } & \multicolumn{7}{|c|}{ Estrato económico } \\
\hline & Alto & $\begin{array}{c}\text { Medio } \\
\text { alto }\end{array}$ & $\begin{array}{c}\text { Medio } \\
\text { alto }\end{array}$ & Obrero & Marginal & Rural & Todos \\
\hline Ninguno & 10.3 & 11.8 & 9.1 & 9.3 & 14.4 & 8.7 & 10.2 \\
\hline $\begin{array}{l}\text { Ayuda, defiende y protege } \\
\text { a la gente }\end{array}$ & 16.7 & 9.6 & 13.6 & 23.0 & 15.5 & 21.0 & 17.4 \\
\hline Defiende los derechos humanos & 10.3 & 15.4 & 8.3 & 4.9 & 8.2 & 4.8 & 8.0 \\
\hline Protege a los niños & 9.0 & 7.4 & 10.6 & 6.6 & 5.2 & 6.1 & 7.3 \\
\hline Protege a las mujeres & 6.4 & 8.1 & 9.1 & 7.1 & 8.2 & 5.7 & 7.3 \\
\hline $\begin{array}{l}\text { Investiga casos y promueve } \\
\text { la denuncia }\end{array}$ & 14.1 & 11.8 & 5.3 & 2.2 & 3.1 & 2.6 & 5.5 \\
\hline Ha tenido presencia & 9.0 & 8.1 & 4.5 & 2.2 & 1.0 & 0.9 & 3.6 \\
\hline $\begin{array}{l}\text { Evita el maltrato de las } \\
\text { autoridades }\end{array}$ & 0.0 & 1.5 & 1.5 & 1.6 & 0.0 & 1.3 & 1.2 \\
\hline Otros logros & 6.4 & 5.9 & 6.1 & 7.1 & 8.2 & 4.8 & 6.2 \\
\hline No sabe & 17.9 & 20.6 & 31.8 & 36.1 & 36.1 & 44.1 & 33.5 \\
\hline
\end{tabular}

En su opinión, ¿cuál es el principal logro de la Procuraduría para la Defensa de los Derechos Humanos en los últimos tres años?

En todo caso, los datos que se exponen como los logros de la Procuraduría muestran que los salvadoreños en general ven con buenos ojos las labores de protección de la ciudadanía. Más aún, la presente evaluación introduce un factor que no ha estado presente en los anteriores sondeos sobre el tema de la Procuraduría: la preocupación por la defensa de los derechos de los niños y las mujeres. Aunque los resultados dan a estos aspectos reunidos no más del 16 por ciento, su sola aparición como logro del trabajo de la Procuraduría mostraría que los salvadoreños han percibido un interés especial por la institución debido a estos aspectos.

Sin embargo, la evaluación del trabajo de la PDDH tiene también un sentido crítico. Aunque casi la mitad de los consultados no supieron esta- blecer los fracasos en la gestión 95-98 del organismo y el 10.1 por ciento opinó que la Defensoría no tuvo reveses, cierta parte de los salvadoreños acordaron implícitamente en decir que la protección a delincuentes, la falta de eficiencia, la parcialidad y la falta de cumplimiento a su misión son algunos de los principales fracasos de la gestión de la Procuraduría (ver Cuadro 5). La parcialidad —o politización, como dieron en llamarla algunos - es una falla atribuida a la PDDH con más reiteración de parte de los ciudadanos de clase alta; en cambio, en los estratos medios prevalece la opinión sobre la falta de eficiencia en el trabajo de la institución, y en los sectores bajos se menciona más la creencia de que la Procuraduría para la Defensa de los Derechos Humanos protege delincuentes. 


\section{Cuadro 5 \\ Principal fracaso de la Procuraduría para la Defensa de los Derechos Humanos en los últimos tres años según variables \\ (En porcentajes)}

\begin{tabular}{|c|c|c|c|c|c|c|c|c|c|}
\hline \multirow[b]{2}{*}{ Variables } & \multicolumn{9}{|c|}{ Principal fracaso } \\
\hline & Ninguno & $\begin{array}{c}\text { Protege } \\
\text { dclincuentes }\end{array}$ & $\begin{array}{l}\text { No son } \\
\text { clicientes }\end{array}$ & $\begin{array}{l}\text { Parcial } \\
\text { politizada }\end{array}$ & $\begin{array}{l}\text { No cumple } \\
\text { su misión }\end{array}$ & $\begin{array}{l}\text { Falta de } \\
\text { apoyo }\end{array}$ & $\begin{array}{c}\text { Poca } \\
\text { expansión }\end{array}$ & $\begin{array}{l}\text { Otros } \\
\text { fracasos }\end{array}$ & $\begin{array}{l}\text { No } \\
\text { s sabe }\end{array}$ \\
\hline \multicolumn{10}{|l|}{ Estrato } \\
\hline Alto & 11.5 & 14.1 & 12.8 & 16.7 & 5.1 & 5.1 & 2.6 & 5.1 & 26.9 \\
\hline Medio-alto & 15.4 & 7.4 & 11.0 & 4.4 & 8.1 & 10.3 & 3.7 & 6.6 & 33.1 \\
\hline Medio-bajo & 9.1 & 9.1 & 9.8 & 5.3 & 6.8 & 8.3 & 3.8 & 5.3 & 42.4 \\
\hline Obrero & 8.2 & 10.9 & 10.9 & 2.7 & 4.4 & 2.7 & 0.0 & 5.5 & 54.6 \\
\hline Marginal & 12.4 & 10.3 & 6.2 & 2.1 & 4.1 & 4.1 & 1.0 & 3.1 & 56.7 \\
\hline Rural & 7.4 & 8.7 & 7.4 & 3.9 & 2.6 & 1.3 & 2.2 & 5.2 & 61.1 \\
\hline \multicolumn{10}{|l|}{ Estudios } \\
\hline Ninguno & 11.8 & 3.9 & 10.5 & 1.3 & 5.3 & 1.3 & 2.6 & 2.6 & 60.5 \\
\hline Primaria & 9.6 & 9.6 & 8.8 & 3.5 & 2.2 & 3.5 & 0.9 & 3.9 & 57.9 \\
\hline Plan básico & 7.4 & 11.0 & 6.6 & 2.9 & 2.9 & 0.7 & 0.7 & 2.9 & 64.7 \\
\hline Bachillerato & o 8.5 & 9.7 & 9.7 & 7.4 & 5.1 & 4.0 & 1.7 & 8.0 & 46.0 \\
\hline Superior & 12.6 & 10.9 & 11.3 & 6.7 & 8.4 & 10.0 & 4.2 & 6.7 & 29.3 \\
\hline Todos & 10.1 & 9.7 & 9.5 & 4.9 & 4.9 & 4.8 & 2.1 & 5.3 & 48.8 \\
\hline
\end{tabular}

En su opinión, ¿cuál es el principal fracaso de la Procuraduria para la Defensa de los Derechos Humanos en los últimos tres años?

Esta opinión, de que la PDDH protege a criminales, no es nueva y tampoco es superficial. Es significativo encontrar que las personas con mayores niveles educativos son algunas de las que soslienen con más frecuencia ese lipo de pensamien10. Es más, las anteriores encuestas ya comenzaban a señalar esa tendencia en la opinión pública salvadoreña (ver Institulo Universitario de Opinión Pública, 1995b). Por ejemplo, una pregunta formulada en otra parte de este mismo sondeo dio como resultado que el 58 por ciento piensa que "los derechos humanos favorecen a los delincuentes y así no se puede acabar con ellos"; eso frente al 25 por ciento que se mostró en contra de esa aseveración (Instituto Universitario de Opinión Pública, 1998). En tal sentido, mucha gente tiene la idea de que los derechos humanos dan prerrogativas a los delincuentes y que ello les permite salir librados de los procesos de justicia. Es difícil identificar el origen de este tipo de pensamiento, pero hay razones para especular que está muy ligado a las declaraciones de algunos funcionarios que públicamente - frente a los medios de comu- nicación- han acusado a la Procuraduría de defender a delincuentes dado el énfasis de ésta por resguardar el debido proceso. La ansiedad social por los niveles que ha alcanzado el país en la posguerra ofrece un fecundo terreno a este tipo de opiniones. Así, los salvadoreños, aunque están conscientes de que los derechos humanos pueden ser útiles para proteger su integridad como personas, llegan a pensar que los más beneficiados son los delincuentes y algunos llegan a identificar a la Procuraduría como la principal responsable de ello.

A pesar de todo, la evaluación que los ciudadanos hacen de la institución es muy positiva. De acuerdo con las respuestas de los consultados, seis de cada diez salvadoreños valoraron de forma positiva ("bueno" o "muy bueno") el trabajo de la PDDH en los últimos tres años; aproximadamente dos de diez lo calificaron de "regular" y uno de esos diez lo evaluaron de forma negativa, esto es, dijeron que el desempeño había sido malo o muy malo (ver Figura 4). 
Figura 4

Evaluación general del trabajo de la PDDH y de la Procuradora en los últimos tres años

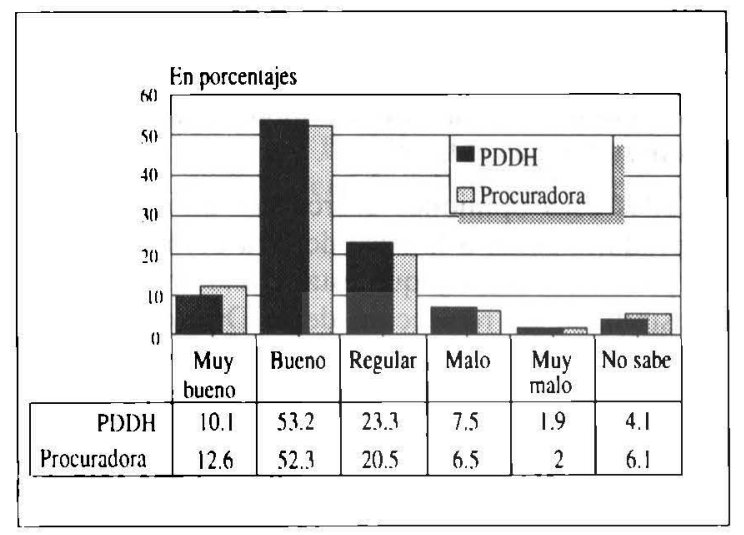

¿Cómo evaluaría usted el desempeño de la Procuraduría para la Defensa de los Derechos Humanos en los tátimos tres años?/¿Cómo evaluaría usted el rabajo de la ahora ex Procuradora de los Derechos Humanos, la Dra. de Avilés?

A diferencia de evaluaciones pasadas a través de encuestas de opinión pública, como la realizada en octubre de 1995 (ver Instituto Universitario de Opinión Pública, 1995b), en esta ocasión, los resultados no registraron diferencias sustantivas en las opiniones sobre la labor de la Procuraduría entre los distintos estratos socioeconómicos. Aparentemente, las opiniones sobre tal institución no muesIran tendencias de opinión en la medida en que se pasa de un estrato social a otro. A pesar de que pueden encontrarse ciertas dilerencias porcentuales entre grupo y grupo, tales variaciones no tienen la solidez esladística necesaria como para decir que las variantes se deben al estrato y no al azar?. Este dato es interesante si se toma en cuenta que no siempre ha sido así en los sondeos anteriores. Según los informes de tales trabajos, las personas de estratos alto o medio-alto solían tener una percepción menos positiva acerca del trabajo de la Procuraduría en comparación con sus conciudadanos de estratos más bajos; ahora no parecen persistir esas diferen- cias. Las opiniones sobre la PDDH se han homogeneizado para todos los sectores socioeconómicos, lo cual sugiere una imagen de la Procuraduría más homogénea que en el pasado - aunque ello no le ha restado cierto carácter polémico. En donde sí es posible encontrar alguna diferencia sustancial es cuando se cruzan estas opiniones por el nivel educativo del entrevistado: los informes sobre los datos muestran que los salvadoreños con nivel educativo universitario o superior evaluaron a la Procuraduría de manera más positiva que el resto de ciudadanos con menor grado de educación. Esto permite pensar que la Procuraduría salió mejor evaluada precisamente por aquéllos que suelen tener más recursos para mantenerse informados.

Ahora bien, la valoración que los ciudadanos hacen de la defensoría nacional está fuertemente ligada a la evaluación que realizan de la Dra. Marina de Avilés, quien dirigió la PDDH en los últimos años. Casi el 65 por ciento de las personas consultadas que conocen la institución estimaron el trabajo de la Procuradora de Derechos Humanos como bueno o muy bueno, el 20 por ciento lo calificó de regular y el 8.5 por ciento dijo que la labor de la funcionaria había sido mala o muy mala. Estos datos muestran que la percepción sobre el trabajo de la Procuraduría no está desligado de la imagen que tienen los ciudadanos sobre la que fue Procuradora entre 1995 y 1998. Sin embargo, los resultados de la evaluación sobre la funcionaria re-

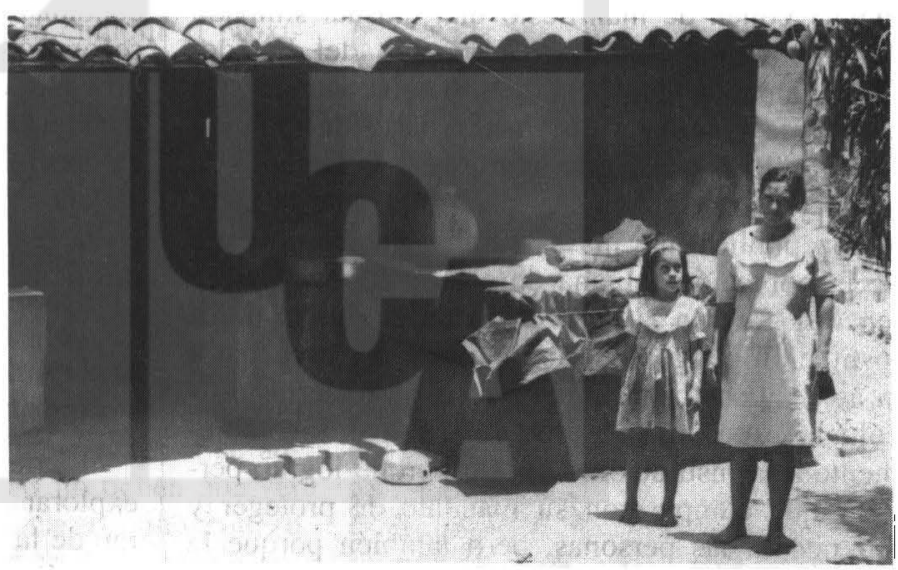

velan que los salvadoreños urbanos de clase media, campesinos y correligionarios del partido FMLN son quienes evalúan todavía mejor a la

3. La prueba clásica de Chi-Cuadrada reportó una $p>0$ 
Procuradora por su desempeño; en estos casos, la visión positiva supera al 65 por ciento de la población encuestada.

La evaluación del trabajo de la PDDH no se quedó ahí. La encuesta del IUDOP exploró también ciertos aspectos del trabajo de la institución durante el trienio de la Dra. de Avilés. A pesar de que en todos los aspectos la evaluación sobre el trabajo de la Procuraduría es bastante positiva, es necesario hacer notar que los elementos mejor valorados fueron el esfuerzo de la Procuraduría por investigar las violaciones en derechos humanos y las resoluciones públicas de la institución. El 67.7 por ciento juzgó como bueno o muy bueno el trabajo de investigar las denuncias de violaciones a los derechos humanos; además, el 68.5 por ciento de los ciudadanos que conocen la Procuraduría para la Defensa de los Derechos Humanos opinaron que las declaraciones y resoluciones públicas de la institución "han sido hechas de manera justa".

Todas estas expresiones positivas acerca de la PDDH ponen de manifiesto una inusual simpatía de la población por un organismo del Estado. Efectivamente, como lo han señalado encuestas anteriores (ver Instituto Universitario de Opinión Pública, 1997), la Procuraduría para la Defensa de los Derechos Humanos es probablemente la institución pública que más confianza recibe de parte de la población. Mucha de esta confianza parece tener su raíz en la percepción de que es la única institución del gobierno con interés por escuchar a la gente y con capacidad de resolverle ciertas dificultades. Así, los salvadoreños evalúan favorablemente a la institución en parte porque logran percibir que cumple con su mandato de proteger y defender a las personas, pero también porque la ven desligada del gobierno. De acuerdo con la pesquisa, casi la mitad de los entrevistados sostuvieron que la Procuraduría funciona de forma independiente del gobierno central, mientras que el 28 por ciento la ve vinculada al gobierno y el resto no opinó al respecto. De hecho, un cruce con los datos de la encuesta reveló -de forma estadísti- camente significativa - que las personas que evalúan de forma positiva a la institución y a la saliente Procuradora de Derechos Humanos suelen percibir con más frecuencia la independencia de ésta con respecto del gobierno; es decir, las opiniones sobre la autonomía del trabajo de la PDDH y las valoraciones favorables sobre la institución están muy ligadas entre sí.

Todas esas opiniones acerca del trabajo de la Procuraduría están a la base de otra opinión recogida por la encuesta y que estaba relacionada con la posibilidad de reelección de la Dra. de Avilés como Procuradora de Derechos Humanos. Al preguntar si dicho personaje debería seguir fungiendo como Procuradora en el siguiente trienio, el 51.3 por ciento contestó que sí, que ella "debería continuar siendo la Procuradora de Derechos Humanos"; mientras que el 23 por ciento se manifestó en contra de la continuidad y el 25.7 por ciento se abstuvo de contestar -por diversas razones. Así, la mitad de la población estaba a favor de que la Dra. de Avilés
continuara en el cargo, frente a una cuarta parte que se opuso. El apoyo hacia la ahora exprocuradora provenía esencialmente de zonas del país como la occidental o el área metropolitana, de sectores campesinos y medio-bajos, de adultos mayores de 40 años de edad, de personas que han estudiado hasta plan básico y de simpatizantes de los partidos de izquierda.

\section{Opiniones sobre los retos del nuevo Procu- rador}

La pesquisa en cuestión se utilizó también para explorar lo que los ciudadanos salvadoreños esperan de la próxima gestión del funcionario al frente de la Procuraduría. Así, se preguntó a los encuestados sobre la principal tarea que debe enfrentar el nuevo Procurador o Procuradora. Los resultados, que se presentan en el Cuadro 6, ponen de relieve el papel de protectora de la población que debe tener la defensoría de los derechos humanos y le adjudican el compromiso de hacer cumplir la ley. 
Cerca del 15 por ciento dijo que la principal tarea del nuevo funcionario debe ser la defensa de los derechos humanos; el 13.2 por ciento mencionó "ayudar a la gente"; el 11.3 por ciento privilegió la necesidad de mejorar el trabajo de la PDDH; el 7.7. por ciento le atribuyó la tarea de terminar con la delincuencia, y el 5.8 por ciento opinó que debe hacer cumplir las leyes, entre otras respuestas.

\section{Cuadro 6 \\ Principal tarea que debe enfrentar el próximo Procurador de Derechos Humanos según estrato socioeconómico del entrevistado}

(En porcentajes)

\begin{tabular}{lrrrrrrr}
\hline & \multicolumn{7}{c}{ Estrato económico } \\
\cline { 2 - 7 } Principal tarea & Alto & $\begin{array}{c}\text { Medio } \\
\text { alto }\end{array}$ & $\begin{array}{c}\text { Medio } \\
\text { bajo }\end{array}$ & Obrero & Marginal & Rural & Todos \\
\hline Defender los derechos humanos & 16.7 & 16.9 & 21.2 & 9.8 & 15.5 & 13.1 & 14.9 \\
Ayudar a la gente por igual & 7.7 & 15.4 & 9.8 & 14.2 & 17.5 & 13.1 & 13.2 \\
Mejorar el trabajo de la PDDH & 11.5 & 14.7 & 10.6 & 14.2 & 5.2 & 10.0 & 11.3 \\
Terminar con la delincuencia & 6.4 & 7.4 & 6.8 & 7.7 & 12.4 & 7.0 & 7.7 \\
Hacer cumplir las leyes y mejorarlas & 11.5 & 6.6 & 6.8 & 7.7 & 2.1 & 3.1 & 5.8 \\
Luchar por la justicia & 6.4 & 3.7 & 6.1 & 3.8 & 6.2 & 4.8 & 4.9 \\
Velar por los derechos de los niños & 9.0 & 2.9 & 5.3 & 3.8 & 5.2 & 4.8 & 4.8 \\
Ser apolítico, independiente & 9.0 & 7.4 & 3.8 & 4.4 & 2.1 & 0.4 & 3.9 \\
Darse a conocer y promover los DH & 6.4 & 6.6 & 6.1 & 1.1 & 2.1 & 2.6 & 3.7 \\
Dar seguimiento al trabajo de la PDDH & 6.4 & 2.9 & 3.8 & 4.4 & 2.1 & 2.6 & 3.5 \\
Investigar a profundidad los casos & 2.6 & 2.2 & 5.3 & 2.2 & 2.1 & 3.9 & 3.2 \\
Otras respuestas & 3.8 & 5.1 & 4.5 & 1.6 & 4.1 & 2.6 & 3.4 \\
No responde & 2.6 & 8.1 & 9.8 & 25.1 & 23.7 & 31.9 & 19.6 \\
\hline
\end{tabular}

En su opinión, ¿cuál es la principal tarea que debe enfrentar el próximo Procurador de Derechos Humanos?

Aparte de los retos o tareas que deberá cumplir el próximo Procurador, se inquirió por las cualidades personales que, según los ciudadanos, debería tener la persona que asuma el cargo. En este caso, las respuestas fueron menos diversas y los consultados acordaron más sobre cinco o seis características particulares. Para un poco más de la tercera parte, el próximo Procurador de los Derechos Humanos debería ser honesto y transparente; le sigue una proporción de 18.6 por ciento que dijo que debería ser defensor de los pobres; el 16.1 por ciento afirmó que debería ser firme en sus decisiones, y el 15 por ciento se pronunció porque el funcionario entrante fuera capaz. Estas opiniones resultan muy interesantes si se advierte que las cualidades más mencionadas no tienen que ver con la capacidad de la persona para el cargo, sino con su probidad e integridad ética para ser defensor de los más necesitados; las habilidades o aptitudes del posible funcionario quedan en un segundo plano frente a la necesidad de que sea trasparente y comprometido con la población. El Cuadro 7 muestra las respuestas a la pregunta según el sector socioeconómico y el nivel educativo de los entrevistados. De acuerdo con dicho cuadro, la honestidad es una cualidad me-

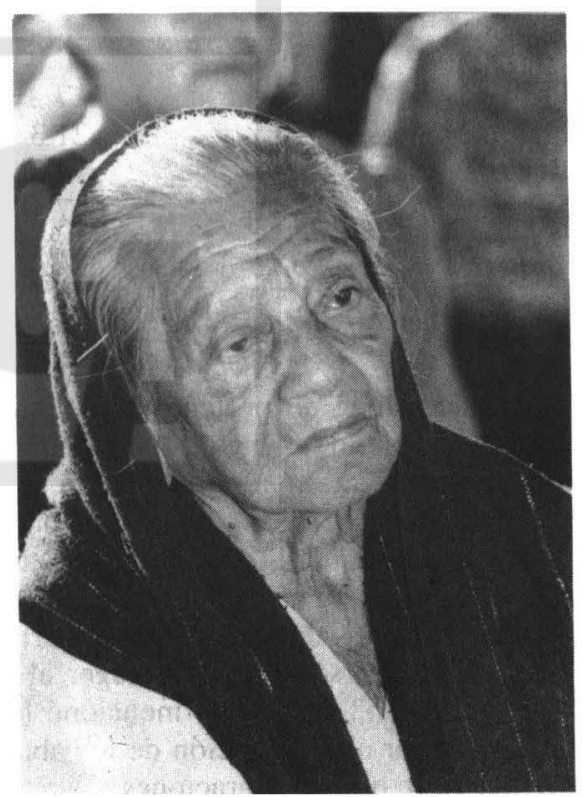


jor valorada en la medida en que se "asciende" en el estrato social; las personas de clase social alta esperan un funcionario transparente en la Procuraduría con mucha mayor frecuencia que los ciudadanos de zonas marginales. En términos de nivel educativo parece mostrarse la misma tendencia aunque con menos intensidad: la probidad aparece como una cualidad más requerida en la medida en que el consultado tiene un mayor nivel de estudios. Sin embargo, la respuesta que aparece más vinculada a los sectores más bajos y de menos formación educativa es la que pide un funcionario que sea capaz de defender a los más pobres. En efecto, las personas con menos recursos sociales tienden a pedir con mayor frecuencia un procurador comprometido con la defensa de los más desposeídos. Este dato es fundamental para comprender lo que buena parte de la población espera del nuevo responsable institucional del respeto de los derechos humanos. Antes que lïmeza, capacidad o independencia, varios salvadoreños quieren un funcionario que pueda protegerlos y ayudarlos en sus problemas cotidianos. Esto sin duda constituyc un complemento a las opiniones que sostenían que el principal reto del próximo Procurador de Derechos Humanos tendría que ser la defensa de los derechos y la asistencia a la gente.

Cuadro 7

Cualidad que debe tener el nuevo Procurador de Derechos Humanos según variables (En porcentajes)

\begin{tabular}{|c|c|c|c|c|c|c|c|c|}
\hline \multirow[b]{2}{*}{ Variables } & \multicolumn{4}{|c|}{ Cualidad } & \multirow{2}{*}{\multicolumn{2}{|c|}{$\begin{array}{cc}\text { Todas las } \\
\text { Inde- } & \text { anterio- } \\
\text { endiente } & \text { res }\end{array}$}} & \multirow[b]{2}{*}{$\begin{array}{c}\text { Otras } \\
\text { res- } \\
\text { puestas }\end{array}$} & \multirow[b]{2}{*}{$\begin{array}{l}\text { No } \\
\text { sabe }\end{array}$} \\
\hline & $\begin{array}{c}\text { Honesto } \\
\text { y trabajador }\end{array}$ & $\begin{array}{l}\text { Defensor } \\
\text { de los } \\
\text { pobres }\end{array}$ & $\begin{array}{c}\text { Firme } \\
\text { en sus } \\
\text { decisiones }\end{array}$ & Capaz. & & & & \\
\hline Estrato & & & & & & & & \\
\hline Alto & 46.2 & 5.1 & 11.5 & 20.5 & 12.8 & 3.8 & 0.0 & 0.0 \\
\hline Medio-alto & 44.1 & 8.1 & 15.4 & 16.9 & 8.8 & 6.6 & 0.0 & 0.0 \\
\hline Medio-bajo & 37.9 & 17.4 & 13.6 & 16.7 & 9.1 & 3.0 & 0.8 & 1.5 \\
\hline Obrero & 34.4 & 19.7 & 19.7 & 15.8 & 5.5 & 2.2 & 1.6 & 1.1 \\
\hline Marginal & 32.0 & 27.8 & 13.4 & 16.5 & 9.3 & 1.0 & 0.0 & 0.0 \\
\hline Rural & 38.9 & 25.3 & 17.9 & 9.6 & 6.1 & 0.9 & 1.3 & 0.0 \\
\hline Estudios & & & & & & & & \\
\hline Ninguno & 36.8 & 32.9 & 10.5 & 13.2 & 5.3 & 0.0 & 1.3 & 0.0 \\
\hline Primaria & 36.4 & 27.2 & 15.4 & 10.5 & 9.2 & 0.4 & 0.0 & 0.9 \\
\hline Plan básico & 38.2 & 21.3 & 16.9 & 12.5 & 4.4 & 4.4 & 2.2 & 0.0 \\
\hline Bachillerato & 40.9 & 14.8 & 19.9 & 17.0 & 5.1 & 0.6 & 0.6 & 1.1 \\
\hline Superior & 39.3 & 7.1 & 15.5 & 19.7 & 11.3 & 6.3 & 0.8 & 0.0 \\
\hline Todos & 38.5 & 18.6 & 16.1 & 15.0 & 7.8 & 2.7 & 0.8 & 0.5 \\
\hline
\end{tabular}

De las siguientes, ¿qué cualidad considera Ud. que deba tener el nuevo Procurador de Derechos Humanos?

La necesidad de proteger la integridad de las personas más vulnerables es un elemento que aparece en varios rubros de la encuesta. Al preguntar sobre el área de los derechos humanos que debe potenciarse más, el 44.1 por ciento señaló que los derechos del niño; el 13.8 por ciento recomendó la protección de los derechos de la mujer; el 12.3 por ciento dijo que se debería proteger al medio ambiente y el 10.2 por ciento mencionó la necesidad de resguardar a la población de los abusos del gobierno, entre otras declaraciones.
Finalmente, la presente investigación de opinión pública encontró que la mayoría de los salvadoreños tienen ciertas ideas de cómo mejorar el respeto a los derechos humanos. En concreto sobresalen tres pensamientos. En primer lugar, la necesidad de crear y aumentar las fuentes de trabajo; en segundo lugar, la urgencia de combatir la delincuencia, de apoyar y fortalecer aquellas instancias relacionadas con la seguridad pública, y tercero, la importancia de educar a la población en los derechos humanos (ver Figura 5). 
No está claro si el primer pensamiento - crear fuentes de trabajo - tiene su raíz en la comprensión ciudadana sobre los derechos económicos de las personas, o si responde a una lógica que muestra la importancia del trabajo en la realización del individuo y el desarrollo de la sociedad, o si está relacionado con la identificación de las causas de la delincuencia; hay razones para pensar que la explicación puede encontrarse en las tres, pero sobre todo en las

últimas dos interpretaciones. Por un lado, los salvadoreños podrían estar valorando la utilidad del trabajo como forma de proveer los derechos fundamentales, pero también podrían advertir la capacidad de las oportunidades laborales para alejar a los individuos de la vida criminal con lo cual asegurarían el respeto de los derechos de los demás. Sin embargo, la necesidad de combatir la delincuencia aparece claramente para varios ciudadanos como una forma de asegurar el respeto a los derechos humanos; la fuerte vinculación entre crimen y violación a los derechos fundamentales predomina en gran parte de la opinión pública salvadoreña. Eso explica algunas afirmaciones obtenidas en el

Figura 5

Opinión sobre lo que debe hacerse para mejorar el respeto a los derechos

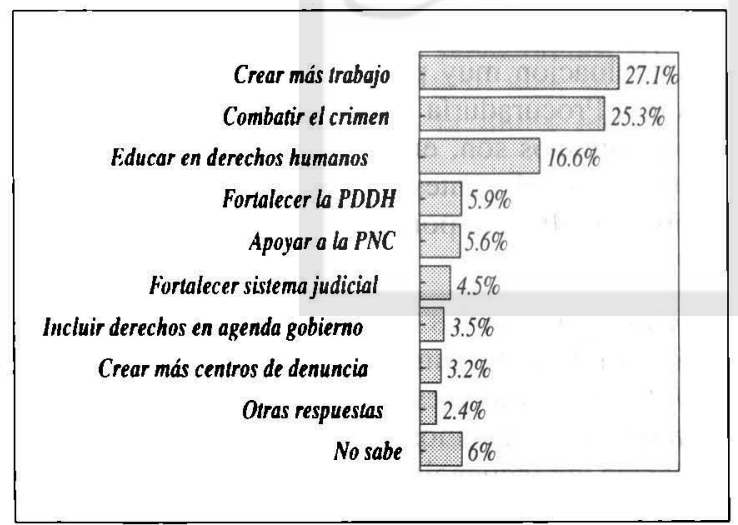

En su opinión. ¿qué debe hacerse para que mejore la siruación de derechos humanos en el país? sondeo y muestra -independientemente de que sea la interpretación más correcta- la imperiosa necesidad de atender el problema de la violencia en el país como forma de asegurar el derecho más básico, el derecho a la vida. Por último, la invitación a educar en derechos humanos subraya la importancia de que los ciudadanos aprendan a vivir sobre la base del respeto para asegurar la protección de la integridad de los mismos ciudadanos.

\section{Opiniones en perspectiva}

Esta evaluación sobre la Procuraduría de Derechos Humanos y sobre el estado de los derechos humanos en el país no estaría completa sino se compararan las opiniones recogidas ahora con las que se recabaron anteriormente. La evolución de las opiniones sobre el tema permiten saber cuánto

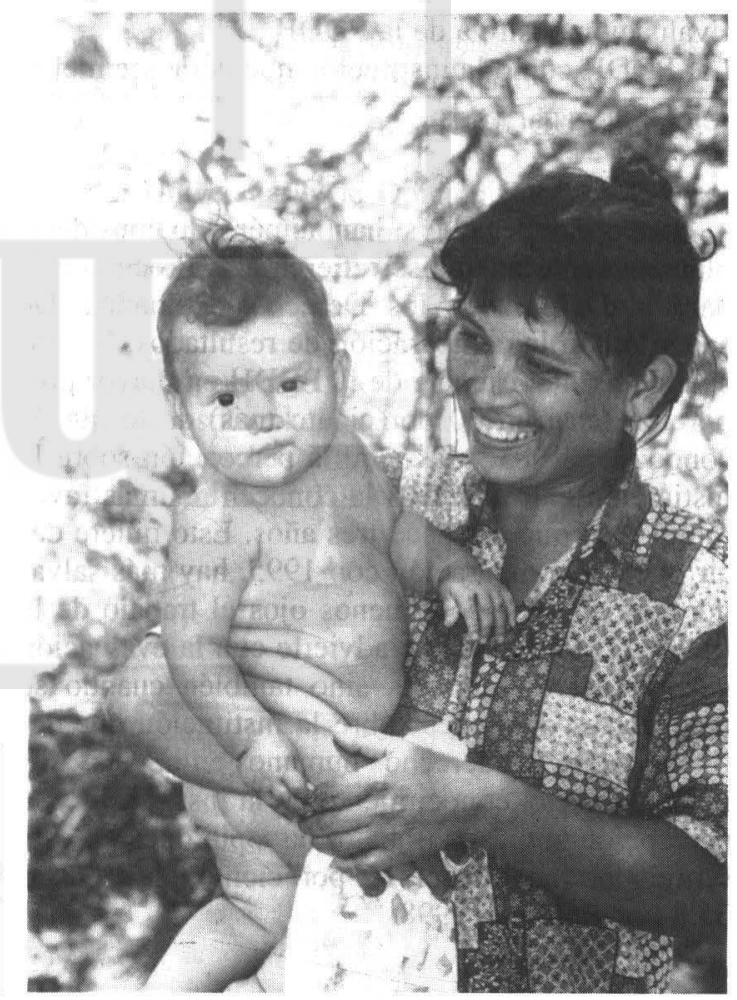


se ha avanzado en la comprensión de los derechos humanos y en la eficacia del trabajo de la Procuraduría.

Las comparaciones se hacen con base en una encuesta similar, llevada a cabo por el IUDOP en marzo de 1995, precisamente cuando finalizó el primer trienio de funcionamiento de la Procuraduría. Un vistazo al Cuadro 8, que presenta la comparación de algunos de los datos más interesantes, permite ver que en términos generales la evolución ha sido positiva. En primer lugar, la percepción de que en El Salvador ha mejorado el respeto por los derechos humanos ha subido del
31.4 por ciento en 1995 al 44.1 por ciento, acercándose a la mitad de la población; también ha aumentado levemente la percepción de que la vida es el derecho humano más importante. La opinión que no parece haber experimentado un aumento y más bien los datos registran una disminución es la que se refiere al papel del gobierno en el respeto a los derechos. Otra opinión que parece estar disminuyendo es la que se refiere a que los derechos humanos favorecen a los delincuentes; la diferencia no es amplia y probablemente se deba a las variaciones del margen de error, pero los datos indican una disminución de tres puntos con respecto a 1995.

\section{Cuadro 8 \\ Opiniones sobre derechos humanos y la Procuraduría en perspectiva}

(En porcentajes)

\begin{tabular}{lrc}
\hline Opinión & $\begin{array}{c}\text { Marzo } \\
1995\end{array}$ & $\begin{array}{c}\text { Febrero } \\
1998\end{array}$ \\
\hline En El Salvador existe respeto por los derechos humanos & 31.4 & 44.1 \\
El respeto a la vida como el derecho humano más importante & 30.6 & 34.9 \\
El gobierno se preocupa por los derechos humanos de todos & 35.1 & 32.6 \\
Derechos humanos favorecen a delincuentes & 61.2 & 58.0 \\
Conocimiento de la Procuraduría de Derechos Humanos & 54.9 & 71.9 \\
Evaluación positiva de la PDDH & 57.3 & 63.3 \\
La PDDH como la institución que defiende mejor los derechos humanos en el país & 15.0 & 35.8 \\
\hline
\end{tabular}

* Fuente: IUDOP, 1995.

Las opiniones que sí han aumentado considerablemente son las que se refieren a la Procuraduría para la Defensa de los Derechos Humanos. De acuerdo con la comparación de resultados, la gente conoce la existencia de la PDDH en mayor proporción (casi un 20 por ciento más) de lo que la conocía en 1995. Más aún, la percepción sobre la institución entre quienes la conocen es más favorable de lo que era hace tres años. Esto quiere decir que, en comparación con 1995, hay más salvadoreños que ven con buenos ojos el trabajo de la PDDH. Esto no sólo se advierte con la evaluación general del desempeño, sino también cuando se recogen las opiniones sobre la institución que defiende mejor los derechos humanos en el país. Alimentada por el conocimiento de la institución y la percepción sobre su trabajo, las opiniones en este sentido ascienden del 15 por ciento en 1995 al 35.8 por ciento en 1998.

\section{Conclusión}

La preocupación por el respeto a la vida, la impresión de que los derechos humanos pueden favorecer a los delincuentes, una percepción de mejoría en el respeto a los derechos humanos y una evaluación muy positiva acerca del desempeño de la Procuraduría para la Defensa de los Derechos Humanos son, en términos generales, los aspectos más relevantes de la encuesta de opinión pública realizada por el IUDOP en febrero de 1998.

Gran parte de los salvadoreños siguen pensando que el derecho humano más importante es el de la vida; esto parece estar vinculado a la preocupación de los ciudadanos por los elevados índices de violencia delincuencial que afectan al país en la actualidad. Los ciudadanos conciben a los derechos humanos como la herramienta que les permite reforzar el derecho que tienen para vivir - no 
se discute tanto si se trata de vivir dignamenteen un contexto que perciben como hostil y poco seguro. Esto explica la preocupación de la ciudadanía por el hecho de que los derechos humanos puedan, en determinadas circunstancias, proteger a ciertos delincuentes en un momento en el cual mucha gente pide "mano dura" para tratar a los criminales. A pesar de que comparativamente con otros años, las cifras que revelan este tipo de opinión parecen haber disminuido levemente, la proporción de personas que tienen este tipo de pensamientos es bastante alta —más de la mitad de la población-. lo que también muestra la falta de conocimiento sobre la utilidad de los derechos humanos de gran parte de los salvadoreños.

Con todo y las confusiones conceptuales que parecen persistir entre los salvadoreños sobre el tema, hay una opinión mayor que en el pasado de que en el país ha mejorado el respeto a los derechos humanos. Esto claramente tiene que ver con la impresión ciudadana de que las motivaciones políticas de la violencia prácticamente han desaparecido de la vida social del país, y de que la mayor parte de amenazas en contra de la integridad de las personas proviene de la delincuencia y no del Estado o de grupos con motivación política. Sin embargo, esta opinión no la comparte la mayoría, dado el anclaje de la opinión sobre el tema de la delincuencia; los datos sugieren que en la medida en que se modifique la percepción pública sobre el estado de criminalidad en el país, en esa medida aumentará la opinión de que los derechos humanos se respetan en el país.

La favorable evaluación que hace la ciudadanía sobre la PDDH es un aspecto que trasluce gran parte de la encuesta. Muchos salvadoreños no sólo piensan que la Procuraduría hizo bien su trabajo, sino que sostienen que es la única institución confiable del Estado. El interés por proteger a las personas más vulnerables, la firmeza de la Procuradora para enfrentar las situaciones de conflicto y la imagen de independencia del resto del gobierno son, a ojos de la población, los aspectos más relevantes del desempeño de la institución. En tal sentido, no es extraño que un poco más de la mitad de los salvadoreños pidieran la permanencia de la Dra. Victoria de Avilés en el cargo de Procuradora. Sin embargo, los salvadoreños mantienen la expectativa de que independientemente de quien sea el próximo funcionario a cargo de la institución, ésta debería concentrarse en la defensa de los más desamparados, en promover los derechos humanos y contribuir al combate de la delincuencia. De esta manera podrá seguir manteniéndose como la única institución del gobierno que reúne la confianza popular.

\section{Referencias bibliográficas}

Instituto Universitario de Opinión Pública (1998). "Encuesta de evaluación de derechos humanos". Serie de informes 67, San Salvador: IUDOP-UCA.

Instituto Universitario de Opinión Pública, (1997). "Encuesta sobre la gobernabilidad y expectativas hacia las nuevas autoridades municipales y legislativas", Serie de informes 64, San Salvador: IUDOP-UCA, Fundación Konrad Adenauer.

Instituto Universitario de Opinión Pública (1995a). "Los derechos humanos en la opinión pública salvadoreña", Estudios Centroamericanos (ECA), San Salvador: UCA, No 558, pp. 351366.

Instituto Universitario de Opinión Pública (1995b). "Sondeo sobre la procuraduría para la Defensa de los Derechos Humanos", Serie de informes 50, San Salvador: IUDOP-UCA. 